\title{
Kepuasan Pasien Pengguna Kartu Jakarta Sehat di Unit Rawat Jalan Rumah Sakit
}

\section{Patient Satisfaction of Jakarta Health Card Users in Hospital Outpatient}

\author{
Caroline MP Hutabarat* Agustin Kusumayati** Gilbert WS Simanjuntak***
}

\begin{abstract}
*Suku Dinas Kesehatan Jakarta Selatan, **Departemen Kesehatan Lingkungan Fakultas Kesehatan Masyarakat Universitas Indonesia, ***Departemen Mata Fakultas Kedokteran Universitas Kristen Indonesia
\end{abstract}

\begin{abstract}
Abstrak
Peluncuran Kartu Jakarta Sehat (KJS) pada bulan November 2012 mengakibatkan jumlah kunjungan pasien yang melonjak drastis di fasilitas kesehatan, khususnya rumah sakit, baik itu rumah sakit pemerintah pusat, rumah sakit pemerintahdaerah maupun rumah sakit swasta yang berkomitmen dengan Pemerintah Daerah Jakarta. KJS memberikan kemudahan akses layanan kesehatan agar pasien dapat berobat secara gratis. Namun persoalan yang muncul kemudian adalah pasien harus mengantre lama di loket pendaftaran, ruang pemeriksaan, maupun ruang pengambilan obat. Penelitian ini bertujuan untuk mengetahui hubungan faktor sosial budaya, pribadi, dan psikologis dengan kepuasan pasien pengguna KJS pada 110 responden di Unit Rawat Jalan RSU UKI, dan telah dilaksanakan pada bulan Maret 2013. Rancangan penelitian yang digunakan adalah deskriptif kuantitatif dengan pendekatan potong lintang. Hasil penelitian menunjukkan kepuasan pasien KJS sebesar 40,9\%. Akses ke rumah sakit, motivasi, informasi baik dan informasi tidak baik berhubungan signifikan dengan kepuasan pasien KJS, tetapi motivasi adalah hal yang paling dominan berhubungan. Selain itu, kepuasan pasien KJS juga berhubungan bermakna dengan pemanfaatan kembali layanan dan minat merekomendasikan layanan pada orang lain.
\end{abstract}

Kata kunci: Kartu Jakarta Sehat, kepuasan pasien, motivasi

\footnotetext{
Abstract

Jakarta Health Card (JHC) was launched on November 2012, followed by sudden increase number of patient in any hospital accordingly. Jakarta Health Card ease the patient to afford health care without payment. We conducted study on the relation among socio-culture, demographic characteristics, and psychology factors toward patient satisfaction in using $\mathrm{JHC}$. The study subjects were 110 outpatient of UKI Hospital, with study design descriptive quantitative with cross sectional approach. The result showed $40,9 \%$ of the patients were satisfied with the hospital service. Factors such as hospital access, motivation, good information and bad information were
}

associated with patient satisfaction significantly, and motivation was the dominant factor. Besides, patient satisfaction also has significant correlation with revisiting/reusing and recommendation of the hospital to other patients. Keywords: Jakarta Health Card, patient satisfaction, motivation

\section{Pendahuluan}

Hakikat penyelenggaraan pelayanan kesehatan adalah untuk memenuhi kebutuhan dan tuntutan para pengguna jasa sehingga menimbulkan rasa puas. Makin sempurna kepuasan pasien, makin baik penilaian terhadap mutu pelayanan kesehatan. ${ }^{1}$ Orientasi kepuasan sangat bersifat individual dan bergantung pada latar belakang individu serta bersifat subjektif. Pasien yang merasa puas terhadap pelayanan kesehatan adalah pasien yang menerima pelayanan kesehatan sesuai dengan yang diharapkan. ${ }^{2}$ Kepuasan pelanggan akan memengaruhi minat untuk memanfaatkan kembali layanan jasa yang sama di waktu yang akan datang. ${ }^{3}$ Pelanggan yang puas akan setia, memanfaatkan dan memperkenalkan produk, juga membicarakan hal-hal yang baik tentang produk itu kepada orang lain. ${ }^{4}$

Pilihan seorang individu untuk membeli dan menggunakan barang atau jasa adalah faktor budaya, sosial, pribadi, dan psikologis. Faktor budaya meliputi subbudaya dan kelas sosial, sedangkan faktor pribadi meliputi karakteristik individu, pekerjaan, gaya hidup, kepribadian, dan konsep diri. Faktor psikologis meliputi motivasi, persepsi, pembelajaran, kepercayaan, dan sikap

Alamat Korespondensi: Gilbert WS Simanjuntak, Departemen Mata Fakultas Kedokteran Universitas Kristen Indonesia, Jl. Letnan Jendral Sutoyo Cawang Jakarta Timur, Hp.0811168237,e-mail: retinaid@yahoo.com 
individu. Apabila konsumen telah membuat suatu keputusan pembelian, konsumen dapat menilai apakah produk atau jasa yang dikonsumsi memiliki kedekatan dengan harapan. Semakin besar kesenjangan antara harapan dan kinerja, semakin besar pula ketidakpuasan. ${ }^{4}$ Beberapa penelitian tentang kepuasan pasien terhadap pelayanan kesehatan telah dilakukan di berbagai negara, antara lain di 39 rumah sakit di Jerman yang menyatakan tingkat kepuasan pasien sebesar $80 \% .^{5}$ Di Muscat, kepuasan pasien terhadap layanan primer sekitar $81 \%$, di India 92\%, pasien rawat jalan di rumah sakit, puas dengan penjelasan dokter.6,7 Sedangkan di Selangor, Malaysia kepuasan pasien terhadap layanan kesehatan publik adalah sekitar $86,1 \% .^{8}$

Program Kartu Jakarta Sehat diluncurkan oleh Gubernur Jakarta pada bulan November 2012, memungkinkan warga yang mempunyai kartu identitas DKI Jakarta untuk berobat gratis. Program ini diduga berkontribusi terhadap kenaikan jumlah kunjungan pasien di unit rawat jalan rumah sakit umum, termasuk di RSU UKI. Masyarakat mengeluh melalui kotak saran mengenai waktu tunggu yang lama dan petugas kesehatan yang kurang ramah. Penelitian ini bertujuan untuk mengkaji tingkat kepuasan masyarakat pengguna Kartu Jakarta Sehat dalam memanfaatkan layanan di Unit Rawat Jalan RSU UKI serta hubungan kepuasan pasien pengguna Kartu Jakarta Sehat dengan berbagai faktor sosial budaya, faktor pribadi, dan faktor psikologis pasien.

\section{Metode}

Penelitian ini menggunakan metode survei dengan pendekatan potong lintang dan dilaksanakan selama bulan Maret 2013. Penelitian dibagi dalam tiga tahap, yaitu persiapan, pengambilan data di lapangan, dan penyusunan laporan dan seminar. Populasi dalam penelitian ini adalah seluruh pasien Unit Rawat Jalan yang berobat ke RSU UKI Jakarta Timur. Subjek disertakan dalam penelitian apabila memenuhi syarat pengguna Kartu Jakarta Sehat, baru pertama kali berobat ke Unit Rawat Jalan RSU UKI, berumur minimal 14 tahun, dan terdaftar dalam register pasien Unit Rawat Jalan RSU UKI. Pasien dengan dua penyakit atau lebih dikeluarkan dari penelitian ini untuk menghindari ketidaksetaraan dengan pasien lainnya. Besar sampel penelitian ini didasarkan pada perhitungan rumus pengambilan sampel dengan nilai baku distribusi normal 0,05 dan presisi sebesar $10 \%$, didapatkan sejumlah 96 subjek. ${ }^{9}$ Akan tetapi, jumlah sampel akan ditambah dengan alasan untuk analisis multivariat diperlukan minimal sepuluh sampel untuk setiap variabel dan mengantisipasi adanya missing data, sehingga jumlah sampel menjadi 110 orang. ${ }^{10}$ Sampel akan dibagi secara proporsional di semua poli rawat jalan berdasarkan proporsi jumlah kunjungan tahun 2012. Selanjutnya, dilakukan uji validitas dan reliabilitas untuk menguji instrumen penelitian.

Penelitian ini menggunakan instrumen pengukuran berupa kuesioner yang disusun dalam daftar pertanyaan. ${ }^{11}$ Bagian pertama berisi karakteristik responden. Bagian kedua berisi satu buah pertanyaan mengenai pengambil keputusan. Selanjutnya, bagian ketiga berisi sepuluh butir pernyataan mengenai motivasi. Kategori jawaban pada kuesioner motivasi ada empat, yakni sangat tidak sesuai, tidak sesuai, sesuai dan sangat sesuai. Bagian keempat berisi pernyataan mengenai informasi tidak baik dan informasi baik yang diterima responden. Masing-masing jawaban pertanyaan diberi skor. Pernyataan informasi tidak baik dan pernyataan informasi baik, terdiri dari lima buah pernyataan. Bagian kelima adalah pernyataan mengenai lima dimensi mutu, yaitu dimensi tangible dan dimensi reliability yang berisikan 7 buah pertanyaan, dimensi responsiveness dan assurance masing-masing 5 buah pertanyaan dan dimensi empathy 3 buah pertanyaan.

Untuk mengukur harapan, jawabannya terdiri atas sangat tidak penting, tidak penting, penting, dan sangat penting. Sedangkan untuk mengukur kenyataan, jawabannya terdiri dari sangat tidak sesuai, tidak sesuai, sesuai, dan sangat sesuai. Bagian keenam dari daftar adalah pertanyaan mengenai perilaku pascapemanfaatan yang terdiri dari sebuah pertanyaan mengenai minat untuk memanfaatkan kembali dan sebuah pertanyaan mengenai minat merekomendasi pada orang lain untuk memanfaatkan layanan kesehatan.

Analisis statistik yang digunakan pada uji bivariat adalah uji kai kuadrat, sedangkan pada multivariat menggunakan uji regresi logistik. Uji validitas dan reliabilitas ini dilaksanakan pada bulan Februari 2013 di Poli Mata RSU UKI pada 30 orang responden. Hasil uji validitas pada semua pertanyaan menunjukkan nilai $r$ hitung yang lebih besar dari $r$ tabel sehingga dinyatakan valid. Demikian pula hasil uji reliabilitas menunjukkan hasil cronbach $\alpha \geq 0,6$, yang menegaskan bahwa semua pertanyaan reliabel.

\section{Hasil}

Hasil analisis pernyataan mengenai kepuasan total, terdapat sebesar 65 orang $(59,1 \%)$ yang tidak puas di Unit Rawat Jalan RSU UKI dan sebesar 45 orang (40,9\%) yang puas pada kelima dimensi mutu (tangible, reliability, responsiveness, assurance dan empathy) Gambaran berdasarkan hasil analisis masing-masing dimensi mutu, tampak seperti dalam Tabel 1. Karakteristik berdasarkan pengambil keputusan untuk menggunakan KJS, demografi dan akses pengguna KJS untuk memanfaatkan layanan rawat jalan di RSU UKI, dapat dilihat dalam Tabel 2.

Berdasarkan motivasi, ada 63 orang $(57,3 \%)$ yang mempunyai motivasi tinggi untuk menggunakan KJS 
Tabel 1. Hasil Analisis Dimensi Mutu Terhadap Kepuasan Pengguna KJS.

\begin{tabular}{llllll}
\hline \multirow{2}{*}{ Dimensi Mutu } & & & & \multicolumn{2}{c}{ Skor Kepuasan } \\
\cline { 5 - 6 } & Kategori & n & $\%$ & \multirow{2}{*}{ Rata-rata } & \multirow{2}{*}{ 95\% CI } \\
\hline \multirow{2}{*}{ Tangible } & Tidak puas & 80 & 72,7 & 76,45 & $74,46-78,45$ \\
& Puas & 30 & 27,3 & & \\
Reliability & Tidak puas & 89 & 80,9 & 74,16 & $72,44-75,88$ \\
& Puas & 21 & 19,1 & & \\
Responsiveness & Tidak puas & 78 & 70,9 & 77,57 & $75,14-80,00$ \\
& Puas & 32 & 29,1 & & \\
Assurance & Tidak puas & 77 & 70,0 & 78,66 & $77,18-80,83$ \\
& Puas & 33 & 30,0 & & \\
Empathy & Tidak puas & 87 & 79,1 & 75,87 & $74,08-77,65$ \\
Kepuasan Total & Puas & 23 & 20,9 & & \\
& Tidak puas & 65 & 59,1 & 76,4 & $74,97-77,32$ \\
& Puas & 45 & 40,9 & & \\
\hline
\end{tabular}

Tabel 2. Karakteristik Responden Berdasarkan Pengambil Keputusan, Demografi, dan Akses ke Rumah Sakit

\begin{tabular}{llll}
\hline Karakteristik & Kategori & n & $\%$ \\
\hline Pengambil keputusan & Diri sendiri & 16 & 14,5 \\
& Rujukan & 94 & 85,5 \\
Usia & < median $(57$ th $)$ & 54 & 49,1 \\
& $\geq$ median $(57$ th $)$ & 56 & 50,9 \\
Jenis kelamin & Laki-laki & 36 & 32,7 \\
\multirow{2}{*}{ Pendidikan } & Perempuan & 74 & 67,3 \\
\multirow{2}{*}{ Pekerjaan } & < SMA & 57 & 51,8 \\
& $\geq$ SMA & 53 & 48,2 \\
Akses ke rumah sakit & Tidak bekerja & 79 & 51,8 \\
& Bekerja & 31 & 28,2 \\
& Sulit & 67 & 60,9 \\
& Mudah & 43 & 39,1 \\
\hline
\end{tabular}

guna mendapatkan layanan di Unit Rawat Jalan RSU UKI. Sebanyak 47 orang $(42,7 \%)$ dengan motivasi yang rendah memanfaatkan KJS untuk layanan kesehatan. Motivasi yang tinggi adalah pengobatan gratis bagi penduduk beridentitas DKI Jakarta, dokter yang melayani memeriksa dengan teliti, petugas memberi pelayanan dengan cepat, dokter memberikan waktu konsultasi yang cukup, dan obat yang diberikan manjur. Pengategorian informasi menjadi informasi tidak baik dan informasi baik. Selanjutnya dibedakan lagi menjadi informasi sedikit dan banyak berdasarkan median. Kedua macam informasi tidak baik dan baik tersebut adalah prosedur pendaftaran, lama waktu tunggu, kebersihan alat medis, keramahan petugas dan ketelitian dokter. Sebanyak 91 orang $(82,7 \%)$ responden memperoleh informasi tidak baik yang sedikit. Sedangkan 19 orang $(17,3 \%)$ responden mendapatkan informasi tidak baik yang banyak. Responden yang memperoleh informasi baik sedikit adalah 77 orang $(70,0 \%)$ dan informasi baik banyak adalah 33 orang $(30,0 \%)$.

Sebanyak 65 orang $(59,1 \%)$ responden yang menyatakan minat yang rendah untuk memanfaatkan kembali layanan kesehatan di Unit Rawat Jalan RSU UKI, dan 45 orang $(40,9 \%)$ menyatakan minat untuk memanfaatkan kembali layanan. Sedangkan, 64 orang $(58,2 \%)$ responden menyatakan minat yang rendah untuk merekomendasikan orang lain untuk mendapatkan layanan di Unit Rawat Jalan RSU UKI, dan sebanyak 46 orang $(41,8 \%)$ menyatakan minat yang tinggi untuk merekomendasikan pada orang lain. Analisis uji bivariat antara faktor pribadi (usia, jenis kelamin, pendidikan, pekerjaan dan akses) dengan kepuasan pasien KJS di unit rawat jalan RSU UKI didapat hasil bahwa hanya akses ke rumah sakit yang mempunyai hubungan bermakna dengan kepuasan pasien KJS di Unit Rawat Jalan RSU UKI. Sedangkan, antara faktor psikologis dengan kepuasan pasien pengguna KJS di Unit Rawat Jalan RSU UKI adalah hubungan yang bermakna antara motivasi pengguna KJS dan informasi baik yang diterima pengguna KJS dengan kepuasan pasien KJS di Unit Rawat Jalan RSU UKI.

Berdasarkan analisis uji bivariat antara kepuasan pasien KJS dengan minat untuk memanfaatkan kembali layanan kesehatan dan merekomendasikan pada orang lain Unit Rawat Jalan RSU UKI, ditemukan hubungan yang bermakna antara kepuasan pasien KJS dengan minat memanfaatkan kembali layanan kesehatan dan minat merekomendasikan pada orang lain Unit Rawat Jalan RSU UKI. Berdasarkan uji multivariat antara faktor sosial budaya, faktor pribadi dan faktor psikologis dengan kepuasan pasien KJS di Unit Rawat Jalan RSU UKI, diperoleh hasil adanya hubungan yang bermakna antara umur, pendidikan, akses, motivasi, informasi tidak baik, dan informasi baik dengan kepuasan pasien KJS di Unit Rawat Jalan RSU UKI, di mana motivasi merupakan faktor yang paling berhubungan dengan kepuasan pasien KJS di Unit Rawat Jalan RSU UKI (Tabel 3 dan Tabel 4).

\section{Pembahasan}

Hasil penelitian ini menemukan tingkat kepuasan pasien pengguna KJS perlu diperhatikan dan diupayakan meningkat, mengingat program KJS yang masih terbilang baru. Tingkat kepuasan di berbagai tempat dapat saja berbeda, karena dapat dipengaruhi berbagai faktor, seperti sosiodemografis, karakteristik, dan psikologis seseorang. Jenis layanan yang sama tetapi karakteristik pasien berbeda, maka tingkat kepuasan dapat berbeda. Selain itu, tidak ada hubungan yang signifikan antara karakteristik dan kepuasan. ${ }^{12,13}$ Kepuasan seseorang adalah perbandingan sesuatu yang ia harapkan dan kenyataan yang diterimanya, apabila kenyataan yang diterima sama dengan harapan, seseorang akan merasa puas, tetapi apabila sesuatu yang diterima lebih dari yang diharapkan, akan merasa sangat puas. ${ }^{4}$ Perbedaan dapat saja timbul karena perbedaan perilaku petugas, prosedur perjanjian, waktu tunggu, dan fasilitas rumah sakit. ${ }^{14}$ Kepuasan pasien KJS di Unit Rawat Jalan RSU UKI yang rendah, padahal layanan yang diberikan gratis, menunjukkan tuntutan pasien yang sedemikian tinggi akan 
Tabel 3. Gambaran Hubungan Faktor Pribadi dan Kepuasan Pasien Kartu Jakarta Sehat

\begin{tabular}{|c|c|c|c|c|c|c|c|c|c|c|}
\hline \multirow{3}{*}{ Variabel } & \multirow{3}{*}{ Kategori } & \multicolumn{6}{|c|}{ Kepuasan } & \multirow{3}{*}{ Nilai $p$} & \multirow{3}{*}{ OR } & \multirow{3}{*}{$95 \% \mathrm{CI}$} \\
\hline & & \multicolumn{2}{|c|}{ Tidak Puas } & \multicolumn{2}{|c|}{ Puas } & \multicolumn{2}{|c|}{ Total } & & & \\
\hline & & $\mathbf{n}$ & $\%$ & $\mathbf{n}$ & $\%$ & $\mathbf{n}$ & $\%$ & & & \\
\hline \multicolumn{11}{|l|}{ Faktor Pribadi } \\
\hline \multirow[t]{2}{*}{ Usia } & $<$ Median & 35 & 64,8 & 19 & 35,2 & 54 & 100,0 & 0,315 & 1,59 & $0,74-3,44$ \\
\hline & $\geq$ Median & 30 & 53,6 & 26 & 46,4 & 56 & 100,0 & & & \\
\hline \multirow{2}{*}{ Jenis kelamin } & Perempuan & 45 & 60,8 & 29 & 39,2 & 74 & 100,0 & 0,75 & 1,24 & $0,55-2,78$ \\
\hline & Laki-laki & 20 & 55,6 & 16 & 44,4 & 36 & 100,0 & & & \\
\hline \multirow[t]{2}{*}{ Pendidikan } & $\geq \mathrm{SMA}$ & 36 & 67,9 & 17 & 32,1 & 53 & 100,0 & 0,105 & 2,05 & $0,94-4,44$ \\
\hline & $<$ SMA & 29 & 50,9 & 28 & 49,1 & 57 & 100,0 & & & \\
\hline \multirow[t]{2}{*}{ Pekerjaan } & Bekerja & 20 & 64,5 & 11 & 35,5 & 31 & 100,0 & 0,610 & 1,37 & $0,58-3,25$ \\
\hline & Tidak bekerja & 45 & 57,0 & 34 & 43,0 & 79 & 100,0 & & & \\
\hline \multirow[t]{2}{*}{ Akses ke rumah sakit } & Sulit & 56 & 83,6 & 11 & 16,4 & 67 & 100,0 & 0,000 & & \\
\hline & Mudah & 9 & 20,9 & 34 & 79,1 & 43 & 100,0 & & & \\
\hline \multicolumn{11}{|l|}{ Faktor Psikologis } \\
\hline \multirow[t]{2}{*}{ Motivasi } & Rendah & 56 & 94,9 & 3 & 5,1 & 59 & 100,0 & 0,000 & & \\
\hline & Tinggi & 9 & 17,6 & 42 & 62,4 & 51 & 100,0 & & & \\
\hline \multirow[t]{2}{*}{ Informasi tak baik } & Banyak & 11 & 57,9 & 8 & 42,1 & 19 & 100,0 & 1,000 & 0,94 & $0,39-2,89$ \\
\hline & Sedikit & 54 & 57,9 & 37 & 40,7 & 91 & 100,0 & & & \\
\hline \multirow[t]{2}{*}{ Informasi Baik } & Sedikit & 53 & 79,1 & 14 & 20,9 & 67 & 100,0 & 0,000 & 9,78 & $4,02-23,79$ \\
\hline & Banyak & 12 & 27,9 & 31 & 72,1 & 43 & 100,0 & & & \\
\hline
\end{tabular}

Tabel 4. Pemodelan Multivariat Variabel Independen

\begin{tabular}{lccccccc}
\hline Variabel & B & SE & Wald & Df & Nilai $\mathbf{p}$ & Exp(B) & 95\%CI \\
\hline Usia & 0,732 & 0,760 & 0,927 & 1 & 0,336 & 2,079 & $0,469-9,229$ \\
Pendidikan & $-1,060$ & 0,750 & 1,996 & 1 & 0,158 & 0,347 & $0,080-1,508$ \\
Akses ke rumah sakit & 1,289 & 0,870 & 2,194 & 1 & 0,139 & 3,629 & $0,659-19,980$ \\
Motivasi & 3,618 & 0,888 & 16,588 & 1 & 0,000 & 37,262 & $6,533-212,516$ \\
Info tidak baik & 0,275 & 1,092 & 0,063 & 1 & 0,801 & 1,316 & $0,155-11,190$ \\
Informasi baik & 1,249 & 0,744 & 2,819 & 1 & 0,093 & 0,034 & $0,811-14,972$ \\
\hline
\end{tabular}

layanan yang diberikan, seperti petugas yang memiliki keterampilan yang baik, berpenampilan rapi, bersikap ramah, mampu berkomunikasi dengan baik, mampu menangani keluhan pasien secara profesional. ${ }^{15}$ Lonjakan pasien menimbulkan beban berlebihan bagi petugas kesehatan dengan jumlah yang tetap sehingga layanan kesehatan menjadi tidak memuaskan bagi pasien, khususnya pengguna KJS di Unit Rawat Jalan RSU UKI.

Pada penelitian ini, motivasi adalah variabel yang paling memengaruhi kepuasan pasien yang merupakan dorongan yang kuat, membuat individu mencari kepuasan atas kebutuhan tersebut. ${ }^{16}$ Motivasi yang rendah pada pasien KJS terletak di masalah antrean yang terjadi saat jumlah pelanggan yang datang melampaui kapasitas sistem dalam melayani. ${ }^{17}$ Program KJS adalah suatu program baru, sehingga diperlukan penyesuaian format pencatatan dan pelaporan yang sesuai dengan petunjuk teknis dari Dinas Kesehatan DKI Jakarta, agar klaim dapat dibayarkan. Akibatnya, pasien mengantre lebih lama.

Motivasi yang tinggi dilandasi oleh dorongan yang kuat dalam diri seseorang untuk menggunakan KJS dalam mendapatkan layanan kesehatan di Unit Rawat
Jalan RSU UKI. ${ }^{16}$ Motivasi seseorang tinggi, karena ia dapat berobat tanpa dipungut biaya. Selain itu, ia yakin dokter akan memeriksa dengan teliti dan obat yang diberikan manjur. Dalam sudut pandang pasien, keterampilan yang dimiliki dokter adalah suatu hal yang penting, di samping efisiensi pelayanan dan perhatian dokter secara pribadi kepada pasien. ${ }^{1}$ Informasi tidak baik yang diperoleh adalah tentang waktu tunggu periksa yang lama, petugas yang tidak ramah dan proses pendaftaran yang berbelit-belit dan lama. Sedangkan informasi baik yang diperoleh responden adalah mengenai ketelitian dokter dalam memeriksa, dan proses pendaftaran yang cepat. Pada saat mempertimbangkan suatu keputusan pembelian, seorang konsumen mencari dan mengolah informasi. Kehadiran informasi produk lain menghasilkan interferensi pada individu tersebut. Selain itu, waktu paparan informasi membuat memori tersimpan lama pada individu. ${ }^{4}$ Ada dua macam proses pencarian informasi, meliputi pencarian informasi sebelum terjadi pembelian (prepurchase search). ${ }^{18}$ Motif dari pencarian informasi ini adalah untuk membuat keputusan pembelian yang lebih baik, sehingga mendapatkan hasil yang memuas- 
kan. Kedua adalah proses pencarian informasi yang berlangsung terus-menerus bahkan sampai ketika proses pembelian telah dilakukan. Motif dari pencarian informasi ini adalah mengumpulkan sebanyak mungkin informasi untuk melakukan pembelian lagi di masa mendatang dan memengaruhi orang lain.

Dalam memanfaatkan kembali layanan, kualitas layanan sangat penting bagi pasien, sehingga bila pasien merasa tidak puas, kemungkinan beralih menggunakan fasilitas layanan kesehatan di tempat lain, karena hampir semua rumah sakit menerima pasien KJS, sesuai instruksi Dinas Kesehatan DKI Jakarta. Begitu pula dengan minat merekomendasi pada orang lain, rekomendasi dari mulut ke mulut sangat efektif untuk memengaruhi orang lain memanfaatkan jasa layanan di suatu tempat. ${ }^{19}$ Pasien yang melaporkan kepuasaan yang lebih tinggi, tampaknya dapat membedakan pengalaman baik dan buruk. ${ }^{20}$ Kepuasaan ini dalam satu penelitian dilaporkan dapat meningkat dengan pemberian informasi tertulis (brosur). ${ }^{21}$ Di tempat lain, ada yang melakukan telefarmasi, dan kepuasan juga meningkat termasuk karyawan rumah sakit. ${ }^{22}$ Sementara peralihan portal catatan medik ke elektronik terbukti tidak selalu meningkatkan kepuasan misalnya karena efisiensi. ${ }^{23}$ Kepuasan pasien meningkat apabila diberi informasi yang cukup, dan dilibatkan saat mengambil keputusan. ${ }^{24}$

\section{Kesimpulan}

Sebagai kesimpulan dapat disebutkan bahwa sebanyak $40,9 \%$ pasien pengguna KJS merasa puas terhadap layanan kesehatan di Unit Rawat Jalan RSU UKI. Akses yang sulit ke tempat layanan kesehatan berpengaruh terhadap kepuasan pasien KJS. Berdasarkan faktor psikologis, faktor motivasi merupakan variabel yang terkuat kaitannya dengan kepuasan pengguna KJS, karena pengobatan yang gratis ke rumah sakit, dokter yang teliti dalam memeriksa dan memberikan waktu cukup untuk berkonsultasi, petugas yang cepat dalam melayani dan obat yang diberikan manjur.

\section{Daftar Pustaka}

1. Azwar A. Menjaga mutu pelayanan kesehatan. Edisi ke-2. Jakarta: Pustaka Sinar Harapan; 1996.

2. Gerson FG, Mengukur kepuasan pelanggan. Jakarta: PPM; 2002.

3. Zeithaml A, Parasuraman A, Berry L. A delivering quality service: balancing customer perception and expectation. New York: The Free Press; 1990.

4. Kotler P, Keller KL. Marketing management, 14th ed. England: Pearson Education Limited; 2012.

5. Schoenfelder T, Klewer J, Kugler J. Determinants of patient satisfaction: a study among 39 hospitals in an in-patient setting in Germany. International Journal for Quality in Health Care. 2011: 23(5): 503-9.

6. Albalushi RM, Sohrabi MR, Kolahi AA. Clients' satisfaction with primary health care in muscat. International Journal of Preventive Medicine. 2012: 3(10): 713-7.

7. Bilkish P, Sangita S, Prakash A, Manjunath K. 2012. A cross sectional study of patient's satisfaction towards services received at tertiary care hospital on OPD basis. National Journal of Research in Community Medicine. 2012: 3(2): 14-8.

8. Ezat S. Customer satisfaction among urban and rural public health clinics in state of Selangor, Malaysia. Malaysian Journal of Public Health and Medicine. 2010: 10(2): 52-67.

9. Lemeshow S, Hosmer D, Klar J, Lwanga SK. Adequacy of sample size in health studies. Chicester: John Wiley and Sons Ltd for WHO; 1990.

10. Katz MH. Multivariable analysis- a practical guide for clinicians and public health researchers. New York: Cambridge University Press; 2011.

11. Hutabarat C. Kepuasan pasien pengguna Kartu Jakarta Sehat di unit rawat jalan RSU UKI tahun 2013 [tesis]. Depok: Universitas Indonesia; 2013.

12. Udonwa NE, Ogbonna UK. Patient-related factors influencing satisfaction in the patient-doctor encounters at the general outpatient clinic of the university of calabar teaching hospital, Calabar, Nigeria. Int J Family Med [serial on internet]. 2012 [cited 2013 January 15]. Available from: http://www.hindawi.com/journals/ijfm/2012/517027/.

13. Allayan S, Mostafa A, Al-Etaibi B, Sorkhou E, Al-Taher H, Al-Weqayyan A. Patient satisfaction with primary health care services in Kuwait. Kuwait Medical Journal. 2008: 40(1): 25-30.

14. Wijono. Manajemen mutu pelayanan kesehatan: teori, strategi, dan aplikasi. Surabaya: Airlangga University Press; 1999.

15. Otani K, Waterman B, Faulkner KM, Boslaugh S, Burroughs TE, Dunagan WC. Patient satisfaction: focusing on "excellent". Journal of Healthcare Management. 2009: 54(2): 93-102.

16. Robbins SP. Organizational behaviour. New Jersey, USA: Pearson Education Prentice Hall; 2005.

17. Tjiptono F. Manajemen Jasa. Yogyakarta: Penerbit Andi; 2000.

18. Sutisna. Perilaku konsumen dan komunikasi pemasaran. Bandung: PT Remaja Rosdakarya; 2003.

19. Setiawan S. Loyalitas pelanggan jasa. Bogor: IPB Press; 2011.

20. Keller AC, Bergman MM, Heinzmann C, Todorov A, Weber H, Heberer $\mathrm{M}$. The relationship between hospital patients' ratings of quality of care and communication. International Journal for Quality in Health Care. 2013: 26(1): 26-33.

21. Alden DL, Friend J, Chun MB. Shared decision making and patient decision aids: knowledge, attitudes, and practices among Hawai'i physicians. Hawaii Journal of Medicine and Public Health. 2013: 72(11); 396-400.

22. Schneider PJ. Evaluating the impact of telepharmacy. American Journal of Health System Pharmacy. 2013; 70(23): 2130-5.

23. Goldzweig CL, Orshansky G, Paige NM, Towfigh AA, Haggstrom DA, Miake-Lye I, Beroes JM, Shekelle PG. Electronic patient portals: evidence on health outcomes, satisfaction, efficiency, and attitudes: a systematic review. Annals of Internal Medicine. 2013: 159(10): 677-87.

24. Ratsep T, Abel A, Linnamagi U. Patient involvement in surgical treatment decisions and satisfaction with the treatment results after lumbar intervertebral discectomy. Eur Spine J [serial on internet]. 2013. Available from: www.ncbi.nlm.nih.gov/pubmed/24249555. 